\title{
Performance of Diamino Fluorophores for the Localization of Sources and Targets of Nitric Oxide*
}

\author{
Juan Rodriguez $\ddagger$, Victoria Specian $\ddagger$, Ronald Maloney $\ddagger$, David Jourd'heuilø, and \\ Martin Feelisch $\$ \S$
}

From the $\$$ Department of Molecular and Cellular Physiology, LSU Health Sciences Center, Shreveport, LA 71130,

and the IICenter for Cardiovascular Sciences, Albany Medical College, Albany, New York 12208

Running title: Performance of DAF-2 for NO Imaging

Key words: nitric oxide, fluorescence, DAF, DAR, ascorbate, glutathione, nitrate, UV

*This work was supported by grants CA 89366 (to DJ) and HL 69029 (to MF) from the National Institute of Health.

$\S$ To whom correspondence should be addressed: Boston University School of Medicine, Whitaker Cardiovascular Institute, 650 Albany Street, X-305, Boston, MA 02118, Tel: 617-4148150, Fax: 617-414-8151, E-mail: feelisch@ bu.edu 


\section{ABSTRACT}

An emergent approach to the detection of nitric oxide (NO) in tissues relies on the use of fluorescence probes that are activated by products of NO autoxidation. Here we explore the performance of the widely-used NO probe 4,5-diaminofluorescein diacetate (DAF-2 DA) for the localization of sources of NO in rat aortic tissue, either from endogenous NO synthesis or from chemically or photolytically-released NO from targets of nitrosation/nitrosylation. Of importance toward understanding the performance of this probe in tissues is the finding that, with incubation conditions commonly used in the literature (10 $\mu \mathrm{M}$ DAF-2 DA), intracellular DAF-2 accumulates to concentrations that approach the millimolar range. Whereas such high probe concentrations do not interfere with NO release or signaling, they help to clarify why DAF-2 nitrosation is possible in the presence of endogenous nitrosation scavengers (e.g. ascorbate and glutathione). The gain attained with such elevated concentrations is, however, mitigated by associated high levels of background autofluorescence from the probe. This, together with tissue autofluorescence, limits the sensitivity of the probe to low-micromolar levels of accumulated DAF-2 triazole (DAF-2 T), the activated form of the probe, which is higher than the concentrations of endogenous nitrosation/nitrosylation products found in tissues. We further show that the compartmentalization of DAF-2 around elastic fibers further limits its potential to characterize the site of NO production at the subcellular level. Moreover, we find that reaction of DAF-2 with $\mathrm{HgCl}_{2}$ and other commonly employed reagents are associated with spectral changes that may be misinterpreted as NO signals. Finally, UV illumination can lead to high levels of nitrosating species that interfere with NO detection from enzymatic sources. These findings indicate that while DAF-2 may still represent an important tool for the localization of NO synthesis, provided important pitfalls and limitations are taken into consideration, it is not suited for the detection of basally-generated nitrosation/nitrosylation products. 


\section{INTRODUCTION}

The discovery in 1987 that nitric oxide (NO) is the signaling molecule responsible for so diverse biological effects such as endothelium-dependent smooth muscle relaxation, nerve cell communication, and antimicrobial defense in macrophages, precipitated a flood of interest in unraveling its full spectrum of actions in physiology and pathophysiology [1-3]. According to the PubMed database, >60,000 scientific studies have already addressed the involvement of NO in biology and medicine. Despite the enormous attention given to the ubiquitous role that this molecule plays in living systems, the mechanisms by which it fulfills these roles often remain unclear. Among the challenges involved in clarifying these mechanisms is the localization of NO sources and targets within a cell. This will require not only a molecular probe with high sensitivity and specificity for NO, but also the chemical and physical interventions to free NO from its biological targets.

Recently, a family of fluorescence dyes became available commercially for the detection of NO, including diaminofluoresceins (DAFs) and diaminorhodamines (DARs) that are purported to deliver low nanomolar sensitivity. These indicators contain a benzoic group attached to a fluorophore that possesses a charge transfer state located energetically between the ground and excited states of the fluorophore moiety, which serves as an effective deactivation pathway for the highly fluorescent excited state $[4,5]$. When nitrosated by reactive nitrogen oxides such as $\mathrm{N}_{2} \mathrm{O}_{3}$ at one of its vicinal amino moieties, an internal diazotation reaction takes place that leads to formation of the corresponding triazole. This chemical modification of the dye by a secondary product of NO is associated with a lowering of the energetic charge transfer state below the ground state of the fluorophore, thus removing the quenching effect of the benzoic structure and allowing the fluorophore to emit efficiently. The high yield of fluorescence of the triazole forms of DAF and DAR make these indicators suitable for the detection of NO production in biological systems, a property that has been exploited by now in many studies using fluorometry [6-17], flow cytometry [18,19], high-pressure liquid chromatography (HPLC) [20], and fluorescence microscopy [4, 14, 20-58]. Furthermore, when used in conjunction with other probes, diamino fluorophores theoretically provide the option to test for co-localization of NO formation with other signaling events, such as a change in intracellular calcium concentration using Fura-2 [12, 16, 38], or its association with certain cell organelles by e.g. the use of MitoTracker to specifically stain for mitochrondria [26,50]. 
The original aim of this study was to assess the viability of the widely-used probe DAF-2 to locate and quantify biological targets of NO in a tissue previously characterized by chemical means, namely in aortic tissue [59,60]. The cellular products, which include RSNO, RNNO, and NO-heme species, are all known to release NO when exposed to light of appropriate wavelengths [60]. We therefore reasoned that exposure to light of wavelengths specific to individual forms of bound NO, in conjunction with DAF-2 incubation, would permit us to image the locations and concentrations of each of these species in intact tissues, with subcellular resolution and nanomolar sensitivity. As we struggled with this seemingly straight-forward proposition, it became apparent that, while the development of diamino fluorophores represent a great analytical advance in NO bioimaging, there are a number of unresolved questions regarding the performance of these probes in biological tissues that impact their utility for the localization of sources and targets of NO. One important issue is that their sensitivity may be significantly limited in biological milieus by reducing agents such as ascorbate (Asc) and reduced glutathione (GSH), since these are known to scavenge nitrosating products such as $\mathrm{N}_{2} \mathrm{O}_{3}$, or their precursor $\mathrm{NO}_{2}$. Several studies $[6,46,66]$ have demonstrated this effect in buffer solutions, in which substantial drops or even a total abolishment of formation of the fluorescent triazole form DAF-2 $\mathrm{T}$ were observed. Yet, only modest inhibition of DAF-2 activation is observed within cultured cells containing comparable levels of reducing agents [66], and all other cell-culture or tissue studies published to date [6-58] document its successful activation. Thus it remains unclear how these probes can be effective in a cellular environment when they seem to perform so poorly in chemical systems of similar composition. A second issue concerns the artefactual activation of DAF-2 by NO photolysed from natural products of NO synthesis, including nitrosothiols, nitrosamines, nitrite, and nitrate [59]. The photolysis of these products is particularly effective with UV light [60, 61], a problem of relevance to experimental setups utilizing illumination optics that unintentionally allow transmission of UV light, or intentionally utilize UV illumination to excite secondary probes, such as Fura-2, for the co-localization of concomitant biochemical events. A third issue relates to the reactivity of the probe with substances commonly used in the NO field to identify targets of nitrosation or nitrosylation, such as mercuric chloride and ferricyanide. A final question, central to the localization of sources/targets of NO, is whether the patterns of fluorescence observed with DAF-2 correspond to sites of activation or compartmentalization of the probe. 
To address these issues, we investigated the nitrosation of the diamino fluorophore DAF2 after loading of rat vascular tissue with its membrane-permeable diacetate analogue, DAF-2 DA, using optical measurements and HPLC analysis. These investigations were complemented with organ bath studies to investigate the functional integrity of dye-loaded tissues, assays for cGMP production to corroborate the production of NO, as well as control measurements performed in isolated buffer solutions. The results presented here help explaining how DAF-2 nitrosation can compete for $\mathrm{N}_{2} \mathrm{O}_{3}$ with Asc or GSH and provide novel insight into its limits of sensitivity for the bioimaging of NO production. Moreover, we demonstrate that UV illumination can lead to significant probe nitrosation through the photoactivation of an NO-related metabolite of hitherto assumed biological inertness, and provide evidence for the chemical origin of the photoactivated species. We also show that substances such as glutathione, mercuric chloride, and ferricyanide, elicit spectral changes in the probe that could be misinterpreted as fluorescence intensity changes. Finally, we demonstrate that the DAF-2 T patterns obtained in vascular tissue are not necessarily correlated to subcellular compartmentalization of NO formation. These new findings add to the growing body of knowledge on how to best optimize their use $[9,10]$ and avoid potential pitfalls [62-66], which will ultimately help investigators to use this relatively new class of fluorophores more judiciously for the investigation of NO-related events. 


\section{METHODS}

\section{Animals}

Male Wistar rats (Harlan) were housed 3/cage in HEPA-filtered cages on cedar bedding and maintained on a 12/12 reversed light/dark cycle. Food consisted of a standard rat chow and was available with water ad libitum. Rats were allowed to acclimatize to their new environment for at least 7 days prior to their use in the study.

\section{Tissue Preparation}

Rats (315-375g) were anaesthetized with diethyl ether and sacrificed by cervical dislocation. After opening of the chest, the thoracic aorta was cannulated at the level of the kidneys and retrogradely perfused at $2 \mathrm{ml} / \mathrm{min}$ with oxygenated $(95 \% \mathrm{O} 2,5 \% \mathrm{CO} 2)$ KrebsHenseleit buffer ( $\mathrm{pH} 7.4,126.8 \mathrm{mM} \mathrm{NaCl}, 5.9 \mathrm{mM} \mathrm{KCl}, 2.5 \mathrm{mM} \mathrm{CaCl} 2,1.2 \mathrm{mM} \mathrm{MgCl} 2,1.2 \mathrm{mM}$ $\mathrm{NaH}_{2} \mathrm{PO}_{4}, 30 \mathrm{mM} \mathrm{NaHCO} 3,5 \mathrm{mM}$ D-glucose, and $1 \mu \mathrm{M}$ indomethacin) to flush the tissue free of blood and prevent intravascular clotting. The aorta was removed and placed in Krebs-Henseleit buffer while trimmed free of adipose and connective tissue, and then cut into 4-5mm rings. Tungsten wire was used to suspend the vascular tissue in a $20 \mathrm{ml}$ organ bath containing oxygenated Krebs-Henseleit buffer at $37^{\circ} \mathrm{C}$. Tissues were allowed to equilibrate for 90min, during which time the buffer was exchanged every 20min, before loading with DAF-2 DA $(10 \mu \mathrm{M}$, Calbiochem) for an additional 60min. In preliminary experiments, other DAF-2 DA concentrations $(0.1,1,30 \mu \mathrm{M})$ and incubation periods (30 and 120min) were investigated for comparison. In instances where inhibition of NO synthesis was necessary, tissues were incubated with $300 \mu \mathrm{M} \mathrm{N} \mathrm{N}^{\varpi}$-(1-iminoethyl)-L-ornithine dihydrochloride (L-NIO) $30 \mathrm{~min}$ prior to loading with DAF-2 DA.

\section{Organ Bath Studies}

Possible interference of DAF-2 with NO formation and/or release and NO-dependent signaling was investigated in endothelium-intact, isolated rat aortic rings using standard organ bath techniques. Vascular relaxation in response to acetylcholine $\left(3 \times 10^{-9}-1 \times 10^{-4} \mathrm{M}\right)$ and papaverine $\left(1 \times 10^{-7}-1 \times 10^{-4} \mathrm{M}\right)$ was investigated in precontracted (phenylephrine, $\left.0.3 \mu \mathrm{M}\right)$ aortic rings with and without prior labeling with DAF-2 DA $(10 \mu \mathrm{M}, 60 \mathrm{~min})$. Changes in isometric tension were measured by means of force displacement transducers and documented on a sixchannel recorder as described. [60]. 


\section{Fluorescence Imaging}

For analysis of fresh tissue, aortic rings were mounted on a coverslip immediately after loading with DAF-2 DA. A drop of PBS was placed on top of the ring to ensure that the tissue remained viable during the subsequent examination. This also allowed for an easy exchange of media in order to test other experimental conditions. A confocal microscope (Radiance 2000 Confocal, Bio-Rad) was used to capture changes in DAF-2 related fluorescence intensity of the tissue, using the $488 \mathrm{~nm}$ line of the Argon laser for excitation in combination with a $515 \mathrm{~nm}$ emission filter. In select studies, the microscopic stage was kept at a temperature of $37 \pm 1^{\circ} \mathrm{C}$ throughout the experiment, and a waiting time of 3 min was allowed to bring the specimen from RT to body temperature.

In an alternative approach, semi-thin frozen sections were prepared in order to allow for repeated testing of multiple interventions on the same piece of aortic tissue. This method allowed us to rapidly preserve tissue integrity without the use of a fixative that could adversely affect the purportedly labile tissue stores of NO. Another advantage of this approach is that consecutive sections could be examined under different experimental conditions, minimizing changes in tissue composition from section to section as occurring in rings of different animals. Aortic rings of $3 \mathrm{~mm}$ width were embedded in O.C.T. Compound (Tissue-Tek), rapidly frozen using Cytocool II (Richard-Allan Scientific) and stored at $-20^{\circ} \mathrm{C}$ for up to 2 months. Blocks with up to 4 vascular rings were then cut into 10 or $20 \mu \mathrm{m}$ thin sections using a cryostat microtome (Tissue-Tek, Miles, Inc.), transferred onto poly-L-lysine coated microscopic slides at $-25^{\circ} \mathrm{C}$ and immediately mounted in PBS, coverslipped and sealed. In some experiments, an NO donor was added at the appropriate concentration to the PBS before coverslipping. Tissue sections were then examined on an inverted fluorescence microscope (Nikon Eclipse TE 300) equipped with a high-pressure mercury lamp, a combination of narrow-bandwidth excitation (490-500nm) and emission (510-530nm) filters (Chroma), and a digital camera (Roper CoolSNAP HQ). To minimize the exposure of our samples to the intense illumination, the shutter was opened just prior to, and closed immediately after, acquiring the image. For calibration purposes, the fluorescence intensity of home-made standards consisting of uniform thin films (120 $\mu \mathrm{m}$ thick) of DAF-2 and DAF-2T at defined concentrations in PBS was recorded under identical imaging conditions. All images were captured under constant exposure time, gain, and offset using IPLab capturing software (Scanalytics, Inc.). 


\section{Image Analysis}

Image analysis was performed using the MetaMorph software package (Universal Imaging). Images from each experimental group were equilibrated to the same threshold value for elimination of background fluorescence and selection of the tissue section as an object in order to determine its total gray value and total tissue area. Increases in fluorescence were calculated from the ratio of total gray value to total tissue area of individual images and expressed as percent of baseline intensity.

\section{Chemical Assays}

An in vitro approach was used to investigate some of the basic chemical interactions of DAF-2 with selected biomolecules and NO standards. A concentration response curve was performed for GSH and sodium ascorbate in the presence of DAF-2 (10 $\mu \mathrm{M}$ and $50 \mu \mathrm{M})$ using $10 \mu \mathrm{M}$ of the NO-donor MAHMA-NONOate, which equates to a maximum yield of $20 \mu \mathrm{M}$ NO. Upon completion of the reaction solutions were transferred to a 96-well microtiter plate and read within 2 min on a fluorescent plate reader (Fluoroskan Ascent, Labsystems; 485nm excitation, $515 \mathrm{~nm}$ emission or FLx800, Bio-Tex Instruments Inc.; 485nm/20 excitation, 528nm/20 emission). GSH-containing DAF-2 solutions were also examined with the aid of a fluorometer (Quanta-Master, Photon Technology International; 480nm excitation).

\section{HPLC and fluorometric analysis of dye content in tissues}

Tissues targeted for fluorometry and HPLC analysis were incubated following the protocols shown in Table 1, including a combination of NO donor (MAHMA-NONOate, $1 \mathrm{mM}$ ), a NOS inhibitor (L-NIO, $300 \mu \mathrm{M}$ ), or exposure to UVA light from a tunable xenon lamp (Melles Griot Spectrum 9000) set to emit at 350nm, with a bandwidth of 30nm and an estimated irradiance of $2 \mathrm{~mW} / \mathrm{cm}^{2}$ at the sample.

Intracellular concentrations of DAF-2 and related compounds, including DAF-2 DA and DAF-2T, were determined subsequent to the incubation protocols outlined in Table 1. These compounds were extracted from the incubated tissues using DMSO $\left(12 \mathrm{~mm}^{3}\right.$ of tissue per $500 \mu 1$ DMSO) under shaking for $1 \mathrm{~h}$ in a water bath at $37^{\circ} \mathrm{C}$. The supernatant (DMSO and solutes) were divided into two aliquots of 400 and $100 \mu$ each, the first of which was used for HPLC analysis, while the second one was used for fluorometric analysis. The products obtained from 
the DAF-2 extracts and the standards were separated by reversed phase HPLC. The samples were injected onto a 250x4.6 mm 5- $\mu \mathrm{m}$ octadecyl silane C18 ultrasphere column (Beckman Coulter, Inc. Fullerton, CA) using a 5 to $40 \%$ acetonitrile - water (TFA, 0.05\%) gradient over 40min at a flow rate of $1 \mathrm{ml} / \mathrm{min}$. Products were detected by UV/VIS absorption at $490 \mathrm{~nm}$. Samples for fluorescence analysis were prepared by dissolving 50 $\mu 1$ of the DMSO extract into $3 \mathrm{ml}$ of buffer (total dilution 1:2,500 relative to original tissue volume), and compared to the fluorescence from a $1 \mu \mathrm{M}$ DAF-2T (Calbiochem) standard. Fluorescence spectra were obtained with a fluorometer (PTI Quanta-Master) at an excitation wavelength of $480 \mathrm{~nm}$.

\section{Action spectrum of light-induced cGMP production in vascular tissue}

Thoracic aortic tissue was obtained from male Wistar rats as described above. Some blood vessels were de-endothelialized by in situ perfusion for $15 \mathrm{sec}$ with $1 \mathrm{~mL} 0.2 \%$ desoxycholate. Tissues were kept in oxygenated $\mathrm{KH}$ buffer for $30 \mathrm{~min}$ at $37^{\circ} \mathrm{C}$ in the dark, followed by incubation for further 30min in the dark in the same buffer additionally supplemented with $0.5 \mathrm{mM}$ isobutyl methylxanthine (IBMX; a phosphodiesterase inhibitor). Thereafter, aortae were divided into six strips of equal length, each strip placed in a separate Petri dish containing oxygenated $\mathrm{KH}$ buffer (intima facing up) and labeled according to their distal position along the blood vessel. All but control strips were illuminated for 60 s with light of distinct wavelengths derived from an HPLC detector (Shimadzu RF-551, flow cell removed, and light coupled into a liquid waveguide, $5 \mathrm{mmx} 2 \mathrm{~m}$ ) and collimated to a spot size of $1.5 \mathrm{~cm}$ at the sample (310-650 nm, $7 \mathrm{~nm}$ bandwidth, 0.34-1.36 $\left.\mathrm{mW} / \mathrm{cm}^{2}\right)$. The order with which strips were exposed to light and the selection of exposure wavelengths followed a randomized process in order to attain an equal representation of distal positions along the vessels, exposure wavelengths, and processing time from extraction of aortae to light exposure.

Immediately after illumination, the segments were snap-frozen in liquid nitrogen. The

frozen samples were homogenized in a porcelain mortar at liquid nitrogen temperature and quantitatively transferred into Eppendorf tubes. Then, $1 \mathrm{~mL} 6 \%$ trichloroacetic acid $\left(\mathrm{TCA}, 4^{\circ} \mathrm{C}\right)$ was added and the sample vortexed for $1 \mathrm{~min}$. Samples were kept on ice and vortexed once more immediately before centrifugation at $14,000 \mathrm{rpm}\left(20 \mathrm{~min} ; 4^{\circ} \mathrm{C}\right)$. The supernatant was transferred with a pipette into new tubes for determination of cyclic guanosine monophosphate (cGMP) and the pellet was suspended in $5 \mathrm{~mL} 0.1 \mathrm{~N} \mathrm{NaOH}$. Protein was determined in $100 \mu \mathrm{L}$ of these samples using a commercially available assay kit based on the Lowry method (BioRad). The 
TCA in the samples was removed by 4-5 x extraction with water-saturated diethylether before the samples were evaporated to dryness (Vortex Evaporator) at $55^{\circ} \mathrm{C}$. The content of GMP in these samples was determined using a commercially available scintillation proximity assay for cGMP (RPA 540, Amersham). Briefly, dried samples were reconstituted in $1 \mathrm{~mL}$ assay buffer, vortexed for $1 \mathrm{~min}$ and diluted with assay buffer to the expected range (1:5, 1:10, 1:100). $100 \mu \mathrm{L}$ of this dilution was used and determinations performed in duplicate. Samples (as well as the cGMP standards) were subjected to acetylation by incubation with $5 \mu \mathrm{L}$ acetylation reagent. Following a $15 \mathrm{~h}$ incubation the samples were transferred to scintillation vials and counted (Beckman LS 6000; 10min interval; window 10-999.0). To account for differences in width and thickness of individual vascular segments the amount of cGMP was normalized to protein content before data averaging

The action spectrum for light-induced cGMP production was obtained through a global error-minimization fitting process performed in Microsoft Excel as follows. Each point on the spectral profile of the action spectrum was treated as a fitting parameter. In addition, each animal was assigned a multiplicative fitting parameter that accounted for the sensitivity that their whole aorta exhibited to light. The product of these fitting parameters was then compared to corresponding cGMP data (basal levels subtracted) obtained from aortic strips through calculation of the square difference normalized to the experimental value. The fitting parameters were then varied iteratively by minimization of the sum of the square differences from all cGMP measurements, using the Solver option in Excel. The resulting spectral profile was corrected for spectral variations in the intensity of the illumination source and expressed as percent changes in cGMP concentration relative to basal levels. 


\section{RESULTS}

\section{Functional studies}

To address the question of whether labeling with DAF-2 DA $(10 \mu \mathrm{M}, 60 \mathrm{~min})$ interferes with NO-related signaling in vascular tissue experiments were performed in isolated rat aortic rings submaximally precontracted with phenylephrine. Using endothelium-intact rings, no significant difference was observed in the degree of contraction to a submaximal concentration $(0.3 \mu \mathrm{M})$ of phenylephrine in the absence and presence of DAF-2 in the tissue $(4.3 \pm 0.2$ vs. $4.2 \pm 0.3 \mathrm{~g})$ while inhibition of basal endothelial NO production by L-NIO $(100 \mu \mathrm{M})$ increased contractile force by $27 \pm 4 \%$ and $25 \pm 7 \%$ under the same conditions $(n=3)$. Moreover, vascular responses to the endothelium-dependent dilator, acetylcholine and the endothelium-independent dilator, papaverine were virtually indistinguishable with and without prior labeling of tissues with DAF-2 DA (data not shown). Additional organ bath experiments were conducted with an intense fiber optic illuminator to elicit light-induced relaxation, as described in Ref. 60, and the tissue responses to light appeared indistinguishable between DAF-2 DA-labeled and unlabeled aortic rings (data not shown). Taken together, these experiments affirm that NO production and signaling remains unchanged in the presence of DAF-2 DA and its hydrolysis product DAF-2, and further suggest that the oxidation of DAF-2 to a radical species capable of directly interacting with NO is likely to be minimal in this particular biological system.

\section{Comparative nitrosation of DAF-2 in buffer solutions and tissue slices}

A number of studies have reported on the nitrosation of DAF-2 for varying concentrations of NO donors, either in buffer solutions [9,10,20,21,30] using fluorometry or in cells/tissues [26,29] using fluorescence microscopy. Fig. 1 shows for the first time a direct comparison between the two, expressed in terms of the fluorescence exhibited at each condition in the absence of NO donors. When measurements are conducted in buffer solutions and analyzed by fluorometry, the data indicates that concentrations as little as $20 \mathrm{nM}$ of the NOdonor MAHMA-NOnoate are capable of eliciting a measurable nitrosation response over the background signal. This is close to the lower limits of detection reported in the literature $[4,9,10,20]$. Our data also shows a DAF-2 response that is linear with increasing concentrations

of NO-donor, as demonstrated by resulting curve fit to $\mathrm{y}=\mathrm{a} \mathrm{x}^{\mathrm{b}}$ which yielded an exponent $\mathrm{b}$ very 
close to unity $(\mathrm{b}=1.01 \pm 0.02)$. The linearity of the response is also consistent with prior reports $[9,10,20,21,30]$.

In contrast to the high NO-sensitivity observed in simple buffer solutions, however, the data shown for thin tissue slices under microscopy suggest that NO-donor concentrations above the micromolar range are needed to elicit a signal above background fluorescence levels. This behavior appears consistent with data previously published on the nitrosation of DAF-2 in cell cultures [26,29]. The DAF-2 nitrosation response we observe displays a sub-linear relationship with respect to increasing concentrations of NO donor, as demonstrated by the value of the exponent to the curve fit $y=\mathrm{ax}^{\mathrm{b}}(\mathrm{b}=0.53 \pm 0.11)$. The deviation from linearity could be due to depletion of oxygen in our sealed samples (coverslipped microscopic sections), caused by the autoxidation of generated NO. Consistent with this assumption, we observed greater increases in fluorescence in experiments conducted in uncovered samples under confocal microscopy, although these still failed to exhibit full linear behavior. The failure to see full linear behavior with aerated samples may indicate that tissue consumption of $\mathrm{O}_{2}$ and $\mathrm{NO}$ may also limit the formation of the triazole form.

\section{Intracellular concentrations of DAF-2,DAF-2 DA, and DAF-2 T, quantified via fluorometry, spectrophotometry, and HPLC}

DMSO extracts derived from the protocols outlined in Table 1 were dissolved in PBS and characterized via fluorometry and spectrophotometry to quantify their contents of DAF-2-related metabolites. All fluorescence spectra, shown in Fig. 2, displayed a profile characteristic of DAF2 emission, including those recorded from basal and L-NIO-treated samples. Since no significant DAF-2 nitrosation is expected in L-NIO treated samples, we infer that its emission arises from either DAF-2, DAF-2 DA, or other DAF-2 related adducts [65]. Spectrophotometric scans revealed spectra resembling those of DAF-2 compounds, with an absorption maximum of about 0.024 near $490 \mathrm{~nm}$. This absorption corresponds to a concentration of $3 \times 10^{-7} \mathrm{M}$, assuming an extinction coefficient of $8 \times 10^{4} \mathrm{M}^{-1} \mathrm{~cm}^{-1}$ for all DAF-2 related products that might be present in the DMSO supernatants. Given the dilution factor of 2,500 from aortic tissue volume to final sample volume, we estimate that the average concentration of all DAF-2 related products in the tissue was $750 \mu \mathrm{M}$. The elevated tissue concentration of DAF-2 reflects the effective conversion of the cell permeable DAF-2 DA into the impermeable form DAF-2, which subsequently is trapped in the intracellular space and thus accumulates over the period of incubation period. 
HPLC measurements performed in aliquots of the same DMSO supernatants directly confirmed that the fluorophore content of all but sample \#5 arose mostly from DAF-2 derived from DAF-2-DA by esterase activity, with smaller amounts $(<20 \%)$ of the parent substance DAF-2-DA. The concentration of all these substances combined totaled about $10 \mu \mathrm{M}$, corresponding to an estimated $400 \mu \mathrm{M}$ of DAF-2 related products in the tissues. This concentration corroborates the elevated levels of DAF-2 related products found using spectrophotometry $(750 \mu \mathrm{M})$. For sample \#5, which was incubated with 1mM of MAHMA NONOate, distribution of DAF-2, DAF-2-DA, and DAF-2-T in the tissue corresponded to 340 $\mu \mathrm{M}, 40 \mu \mathrm{M}$, and $120 \mu \mathrm{M}$, respectively.

\section{Actions of Asc and GSH on DAF-2 activation}

Addition of Asc or GSH resulted in inhibition of DAF-2 T formation, as shown in Fig. 3. The efficacy of inhibition was determined from a curve fit of the concentration response curves shown in Fig. 3 to an equation of the form

$$
\text { Fluorescence }([x])=\frac{\text { Fluorescence }([0])}{1+[x] / I C_{50}}
$$

where $[\mathrm{x}]$ is the concentration of Asc or GSH in the sample. The fits showed that the Asc response curve followed the above equation very closely, whereas the GSH fits showed significant departures from the equation at higher concentrations. For the $10 \mu \mathrm{M}$ DAF-2 solutions, Asc was found to be a more effective inhibitor of DAF-2-T formation than $\mathrm{GSH}$ (IC $\mathrm{I}_{50}$ $25 \mu \mathrm{M}$ vs. $200 \mu \mathrm{M}$ respectively). These values are in qualitative agreement with those reported by Espey et al [67] ( $\mathrm{IC}_{50} 2 \mu \mathrm{M}$ vs. $90 \mu \mathrm{M}$ respectively) employing the NO-donor DEA/NO. Importantly, our results reveal that the amount of triazole formed in the GSH-containing samples increases 3-4 fold when the concentration of DAF-2 is increased to $50 \mu \mathrm{M}$ while the concentration of NO-donor was kept constant (see Fig. 3b). The increased DAF-2-T formation indicates that the competition between GSH and DAF-2 for NO autoxidation species is more favorable toward DAF-2 when this probe is present at higher concentration.

Our results also indicated a possible interaction between DAF-2 and GSH, at GSH concentrations higher than the ones shown in Fig. 3b. Addition of 10mM GSH not only inhibited the formation DAF-2 T, but also resulted in spectral broadening of the fluorescence, which were not transient in nature. The broadening effect resulted in artifactual increases in fluorescence at 
wavelengths away from the emission peak, and opposing behavior near the peak. Thus caution should be exercised when interpreting DAF-2 T fluorescence changes under elevated GSH concentrations, particularly in the absence of accompanying spectral data.

\section{Sensitivity to $\mathrm{HgCl}_{2}$}

A common approach to determination of RSNO content in a sample involves a duplicate measurement with and without preincubation with mercuric chloride. The addition of $\mathrm{HgCl}_{2}$ to a sample is thought to result in the cleavage of the S-NO bond of nitrosothiols due to the high affinity of mercuric salts for sulfur and thus to a reduction in NO signals derived from RSNOs. Our studies revealed that pre-incubation of aortic tissues with $0.1 \% \mathrm{HgCl}_{2}$ (final concentration $3.7 \mathrm{mmol} / \mathrm{L}$ ) followed by DAF-2 DA resulted in a 3-fold increase in fluorescence compared to those incubated with DAF-2 DA only. A similar increase in fluorescence was obtained when a drop of $0.2 \% \mathrm{HgCl}_{2}$ was added to DAF-2 DA incubated tissue slices under the microscope. No increase in fluorescence was observed when the same experiment was performed with tissues that were not incubated with DAF-2 DA.

Additional experiments were conducted in the absence of a biological matrix, i.e. in buffer solutions, to better understand the nature of this fluorescence increase. Addition of $0.2 \%$ $\mathrm{HgCl}_{2}$ to a buffer solution containing $10 \mu \mathrm{M}$ of DAF-2 only resulted in a 4-fold increase in fluorescence, as monitored with a fluorometer. Importantly, the addition of the mercury salt resulted in a red shift of the fluorescence spectrum by about $12 \mathrm{~nm}$ and a double-banded absorption spectrum between 400 and $500 \mathrm{~nm}$. These observations suggest that DAF-2 DA reacts with $\mathrm{HgCl}_{2}$ to form a new product with a modified absorption/emission spectrum and a higher quantum yield of fluorescence. This phenomenon may therefore account for the increase in fluorescence seen in tissue slices upon addition of $\mathrm{HgCl}_{2}$.

Although no attempts were undertaken to characterize in detail the nature of interaction with other reagents commonly used in NO research, preliminary results with ferricyanide, Nethylmaleimide, and Tempol, seem to indicate that these compounds may also interfere with DAF-2 fluorescence (data not shown).

\section{Compartmentalization of DAF-2 $T$ in aortic tissues}

Microscopic slices of aortic tissue incubated with DAF-2 DA were exposed to concentrated solutions of MAHMA-NONOate in order to identify spatial patterns of DAF-2 
arising from compartmentalization of the probe or of the nitrosating agent $\mathrm{N}_{2} \mathrm{O}_{3}$. Figure 4 a shows the pattern obtained with addition of $200 \mu \mathrm{M}$ MAHMA-NONOate. Identical laminar patterns were obtained at other concentrations, ranging from $200 \mathrm{nM}$ to $20 \mathrm{mM}$, but with a concentrationdependent intensity. A similar pattern was observed when tissues were double-stained with haematoxylin/eosin (H\&E staining) as shown in Fig. 4b, indicating that DAF-2 T formation in aortic tissue is largely focused in or around elastic laminae. Even in the absence of NO donors, i.e. under basal conditions, it was still possible to observe a pattern of DAF-2 $\mathrm{T}$ formation that was still largely focused around the elastic laminae (see Fig 4c), with overall higher intensities near the endothelium. Interestingly, this pattern is preserved but the brightness intensified with increasing exposure to UV light (Figs. 4d and 4e).

\section{Action spectrum of intracellular DAF-2T formation under intense UV-VIS exposure}

DAF-2 DA incubated aortic tissue, exposed to UV radiation of $350 \mathrm{mn}$, responded with significant increases in DAF-2T formation as exemplified in Figs. 4d and 4e. Similar responses were observed for other wavelengths of light ranging from $310 \mathrm{~nm}$ to $450 \mathrm{~nm}$. The resulting action spectrum, when normalized to the spectral output of the light source over the same spectral range, shows that the light induced DAF-2T formation appears to be most effective at the lowest wavelengths (Fig. 5a). A qualitatively similar trend is reflected in the action spectrum for cGMP production (Fig. 5b). 


\section{DISCUSSION}

The results from the present study have revealed factors of chemical, biochemical, and physical origin that impact the ability of DAF-2, and generally other diamino fluorophores, to image sources and targets of NO in tissues. In what follows, we discuss these factors separately and consider ways to address ensuing limitations.

\section{What is the true sensitivity of DAF-2 for imaging NO sources and targets?}

The elevated concentration of DAF-2 that accumulates in tissues incubated with DAF-2 DA, however advantageous toward the competition with endogenous antioxidants for nitrosating agents, brings an undesired background signal that diminishes the sensitivity of the technique for the detection of NO. This limitation may arise from the intrinsic fluorescence of the inactivated probe DAF-2, or from reaction products of DAF-2 with intracellular substances such dehydroascorbate [66]. The presence of background fluorescence is evident in the results shown in Fig. 2, which show that tissues incubated with DAF-2-DA always exhibit some level of DAF2-like fluorescence, even when NO production is inhibited with L-NIO. The similarity in fluorescence intensity between the basal and the L-NIO treated sample also suggests that a large component of the fluorescence observed under basal conditions arises from background emission related to DAF-2.

Closer quantitative consideration of the results shown in Fig.2 suggests that the background emission indeed arises from DAF-2 autofluorescence. This interpretation is arrived at by comparing the emission between the $100 \mathrm{nM}$ DAF-2 $\mathrm{T}$ standard and the L-NIO-treated tissues as follows. According to Fig. 2, the emission from the DAF-2 T standard is 125-fold greater than that of the L-NIO-treated aortas, suggesting that the emission from the NOSinhibited tissue sample is equivalent to that of $0.8 \mathrm{nM}$ DAF-2 T. Since the latter was diluted by a factor of 2,500 relative to the original aortic concentration, the estimated emission emanating directly from the tissue should be equivalent to that of $2 \mu \mathrm{M}$ of DAF-2-T. Compared to the 400 and $750 \mu \mathrm{M}$ concentration of DAF-2 determined by HPLC and spectrophometry, respectively, the emission thus represents a fraction of 0.003-0.005 of the total emission that could be produced if all DAF-2 fluoresced with unity quantum yield. This fraction is in fact remarkably similar to the fluorescence quantum yield of DAF-2, which has been reported to be 0.005 [4]. This estimate indicates that the background emission arises from DAF-2 autofluorescence, which 
despite its low quantum yield becomes significant owing to its large accrued concentration in the tissue. The finding that this background emission is equivalent to the activation of $2 \mu \mathrm{M}$ of DAF2-T within the tissue attests to its significance and potential for interfering with the detection of DAF-2 $\mathrm{T}$ formation. The importance of DAF-2 autofluorescence was first pointed out by Leikert et al [9] and Rathel et al [10] in the context of DAF-2 in tissue perfusates, which our results now extend to tissue NO bioimaging.

The level of interference due to DAF-2 autofluorescence depends ultimately on the exactness with which this background emission can be subtracted from the total fluorescence emanating from the sample. Factors such as quantum noise and excitation lamp fluctuations can lead to variations in autofluorescence intensity from one time point to the next that obscure small changes in DAF-2 $\mathrm{T}$ formation, particularly when the fluorescence spectrum of DAF-2 $\mathrm{T}$ cannot be distinguished from DAF-2 autofluorescence. The magnitude in the fluctuations of the latter can thus be equated with the limit of sensitivity for detection of the former. For the instrumentation used in this study, we determined that the magnitude of the fluctuations for these factors are typically on the order of a few percent, leading to a detection limit for the ratio of (DAF-2 T fluorescence)/(DAF-2 autofluorescence) of a few 0.01. In the case of DAF-2 T formation in buffer solutions (see curve fit in Fig.1a), this ratio appears to be attained when the concentration of MAHMA-NONOate reaches the low $\mathrm{nM}$ level. This estimate for the minimal detectable level of an NO-donor in a buffer solution is in fact consistent with the sensitivity usually quoted for this probe. However, in the case of DAF-2 nitrosation in tissues (see curve fit in Fig 1b), the corresponding minimal detection level for the above ratio appears to occur in the low $\mu \mathrm{M}$ region of MAHMA-NONOate, i.e., roughly 3 orders of magnitude higher than the corresponding levels in buffer solutions.

The lower-than-expected sensitivity of DAF-2 implied by Fig.1b imposes significant limitations on the number of biochemical NO-targets that can be imaged with this probe, at least for those generated in vivo under basal conditions. According to Bryan et al [59], the basal levels of many endogenous nitroso/nitrosyl species (i.e. nitrosothiols, nitrosamines, and hemeNO products) typically range from low-nanomolar to hundreds of nanomolar. If the detectability of DAF-2 $\mathrm{T}$ is truly in the micromolar range in tissue samples, then all of these products fall below the limit of detection. Nitrite, which is now gaining interest as a biologically-active NOproduct [68], can reach low micromolar levels in brain and aortic tissues and hence this product may be at the limit of detection in those tissues. Nitrate, which is found at levels ranging from a 
few to tens of micromolar across different tissues [59], is best suited to be imaged with the limited sensitivity of DAF-2, although this NO-product holds little biological activity. Lastly, the micromolar detectability of DAF-2 $\mathrm{T}$ in tissue samples also has important implications for the localization of NO sources and associated real-time capability. Given that NO fluxes from biological sources are typically estimated to be in the lower $\mu \mathrm{M} / \mathrm{min}$ range, the limited sensitivity of DAF-2 implies that the minimum accumulation time for the detection of a signal may be measured in minutes rather than in seconds. Such a delayed response could limit applicability of this probe to NO-signaling in tissues.

\section{Do antioxidants such as GSH or Asc affect DAF imaging?}

Prior investigations have called attention to the quenching of DAF-2 nitrosation by naturally occurring reducing agents such as Asc and GSH [7,46,67]. Consistent with these findings, our results indicate that the presence of millimolar concentrations of such substances in media containing $10 \mu \mathrm{M}$ of DAF-2, leads to a substantial reduction in triazole formation to levels that could undermine the use of this fluorophore in vitro. However, at higher DAF-2 concentrations, much of this inhibition can be mitigated by a greater efficiency of NO capture, as demonstrated in Fig $3 \mathrm{~b}$ for $10 \mu \mathrm{M}$ vs $50 \mu \mathrm{M}$ DAF-2. Therefore, at DAF-2 concentrations approaching $1 \mathrm{mM}$ one might expect very effective probe activation that could essentially mitigate quenching effects by other molecules. Thus it seems that the scavenging action of Asc and GSH may not necessarily undermine the efficacy of DAF-2 as previously feared. This finding may account in part for the observation made by Espey et al. [67] that intracellular DAF-2 T formation in cell cultures was only modestly affected by GSH depletion following buthionine sulfoximine (BSO) treatment, whereas buffer solutions with equivalent changes in concentrations of GSH exhibited dramatic changes.

\section{Is DAF-2 compartmentalized in tissues?}

The spatial patterns of fluorescence observed in this study establish another important issue concerning compartmentalization of fluorescence signals within tissues. A typical fluorescence pattern in tissue from large arterial blood vessels, shown in Fig 4a, is characterized by the presence of strongly fluorescent strands, despite uniform application of MAHMA-NO NOate over the entire surface of the sample. This pattern is strikingly similar to the morphology of elastic laminae in this tissue that are readily seen using H\&E staining (see Fig 4b). The 
similarity strongly suggests that the emission of DAF-2 $\mathrm{T}$ from aortic tissue originates predominantly from the elastic laminae. One potential mechanism that accounts for the localization of the emission could be linked to enhanced $\mathrm{N}_{2} \mathrm{O}_{3}$ production occurring within the hydrophobic environment of the lamina [69]. Alternatively, it may simply reflect preferential accumulation of the fluorophore within elastic fibers. Although this process has never been characterized specifically for the interaction between DAF-2 and the components making up the elastic laminae, the information available for the interaction between fluorescein and collagen (dissociation constant $\mathrm{K}_{\mathrm{d}}=1.8 \mu \mathrm{M}$ ) [70] indicates that this type of fluorophore binds strongly to these proteins. Regardless of the mechanism involved, the images obtained in this study with broadly-distributed NO sources serve as a vivid reminder that fluorescence DAF-2 T patterns do not necessarily correlate with local NO production. This issue is further complicated by the finding that DAF-2 is subject to oxidation to a radical cation that can directly trap NO [64, 65]. Such processes are expected to occur preferentially at highly redox-active cell organelles such as mitochondria [71], which might contribute to the formation of "hotspots" or "punctate emission" of NO-related DAF-2 fluorescence previously attributed to NO formation within this particular cell organelle [26].

\section{Can targets of NO be detected through photolysis?}

In addition to elucidating the consequences of elevated intracellular concentrations of DAF-2, our study also provides new insight into the interaction of UV light with tissues and its effect on the nitrosation of DAF-2. This interaction produces a fluorescence enhancement in tissues incubated with DAF-2-DA that is consistent with the formation of DAF-2-T (see Fig. 2). The same effect is seen under microscopy, as depicted in the time sequence Figs 4c-4e. Furthermore, the resemblance between action spectra for DAF-2 $\mathrm{T}$ and cGMP productions during illumination, shown in Fig. 5, strongly suggest that NO is being generated via photolysis from a UV-absorbing species with an absorption peak below $310 \mathrm{~nm}$. These action spectra are consistent with that of nitrate photolysis $\left(\lambda_{\max }=302 \mathrm{~nm}\right)$, which in fact has been shown recently to produce significant levels of NO when illuminated with UV light in the presence of thiols [61]. The identification of nitrate as the source of photolysis, and its distribution in aortic tissue as implied in Figs 4d and 4e, could also have important biological implications. The evidence shows that nitrate is distributed deep into the tissue with maximal levels found near the endothelium, suggesting that tissue nitrate concentrations are a biochemical correlate of local 
steady-state levels of NO. Given that plasma contains relative little nitrate compared to aortic tissue [59], and assuming that nitrate is capable of diffusing freely across the tissue, one would have expected layers in contact with blood to be drained of nitrate rather than maximally loaded with it. The lack of evidence for drainage of nitrate in these layers therefore suggests that nitrate does not necessarily diffuse freely across tissues, at least not in aortic blood vessels.

\section{Final remarks}

Although not directly related to the main aim of this study, the above findings provide a framework for rationalizing why the $10 \mu \mathrm{M}$ incubation concentration of DAF-2 DA, first suggested by Kojima et al [4], may be an optimal concentration for the observation of triazole formation in tissues. Given the resulting intracellular accumulation of DAF-2 shown here to approach $1 \mathrm{mM}$, the extinction coefficient for DAF-2 of about $79,000 \mathrm{M}^{-1} \mathrm{~cm}^{-1}$, and the thickness of tissue slices typically used in most studies $(10-20 \mu \mathrm{m})$, one estimates the DAF-2 absorption through a DAF-2 DA stained sample to reach 0.08-0.15 OD. Increasing the concentration further could therefore result in significant re-absorption of the fluorescence produced within the sample. Additionally, as the intracellular concentration of DAF-2 increases to $1 \mathrm{mM}$, the mean separation between probes decreases to distances on the order of $10 \mathrm{~nm}$. Such distances begin to rival those of the Forster radii for most fluorophores $(\sim 5 \mathrm{~nm})$ below which energy transfer from highly fluorescent DAF-2 $\mathrm{T}$ to low-emitting DAF-2 should dominate. This process would effectively quench the fluorescence derived from DAF-2 nitrosation.

Zhang et al. [66] have recently published a comprehensive study on the formation of DAF-2 complexes with ascorbate and dehydroascorbate, and on their potential for interfering with the fluorescence from DAF-2T. Although this issue was not addressed directly in our study, the fluorescence measurements derived from DMSO extracts (Fig. 2) and the results obtained from aortic tissues incubated with DAF-2 DA indicate that DAF-2 autofluorescence fully accounts for the observed background emission and that ascorbate adducts may not interfere significantly with DAF-2-T detection in this particular biological specimen. Although we see no evidence in the present study of ascorbate-related products in rat aorta, this conclusion cannot be generalized to other tissues. As pointed out by the authors, and confirmed with measurements by our group [72], ascorbate levels vary significantly across the organ system of rats, ranging from $<100 \mu \mathrm{M}$ in the aorta to $\sim 2 \mathrm{mM}$ in the brain. Thus, it is still conceivable that the DAF-2 
complexes formed with ascorbate or dehydroascorbate could interfere with DAF-2 assays in biological tissues other than the one studied here.

A final point should be made concerning the possible use of additional spectroscopic information to offset some of the artifacts encountered in this study. As our study demonstrated, the presence of $\mathrm{GSH}$ or $\mathrm{HgCl}_{2}$ can trigger spectral shifts and quantum yield changes in the emission of DAF-2. Such changes could be misinterpreted by single-wavelength detection systems as increased or decreased DAF-2 $\mathrm{T}$ formation. However, using microscopy systems equipped with wavelength-tunable filters (spectral imaging) combined with multi-wavelength analysis, it should be possible to separate the contributions due to spectral artifacts from those due to DAF-2 $\mathrm{T}$ formation. However, the tunable filters required to achieve this form of microscopy are costly and the multi-wavelength analysis may require a significant investment of time to develop. An additional improvement that could potentially eliminate the interference due to DAF-2 autofluorescence is the incorporation of a technique capable of differentiating between species with low fluorescence lifetimes, such as DAF-2, and high fluorescent lifetimes, such as DAF-2 T. Fluorescence lifetime imaging microscopy is also available commercially, although these systems constitute a costly alternative to conventional fluorescence microscopy.

In summary, this study describes important considerations and limitations in the use of diamino fluorophores for imaging sources and targets of NO. A main finding is that incubation of tissue with DAF-2 DA produces intracellular concentrations of DAF 2 that approach the mM range. Such a high concentration is beneficial, inasmuch as it enables the probe to compete with scavenging by cellular antioxidants (Asc, GSH), but detrimental as its autofluorescence contributes significantly to the overall background fluorescence from tissue samples. The resulting loss in sensitivity (approaching 3 orders of magnitude compared to those in buffer solutions) make detection of sources and targets of NO in tissues by fluorometry difficult under basal conditions. Our study also demonstrates that DAF-2 can be activated by NO generated from UV photolysis of a substance with an action spectrum similar to nitrate. These findings

provide a better insight into key factors that affect the performance of such probes for NO bioimaging.

\section{Acknowledgements:}

We are grateful for help with the cGMP experiments from Nisha Singh and valuable advice on confocal microscopy from Dr. Robert Specian. 


\section{Performance of DAF-2 for NO Imaging}

\section{REFERENCES}

1. Moncada, S.; Palmer, R.M.J.; Higgs, E.A. Nitric oxide: physiology, pathophysiology, and pharmacology. Pharmacol. Rev. 43:109-42, 1991.

2. Snyder, S.H.; Bredt, D.S. Sci. Am. Biological roles of nitric oxide 266:(5), 68-77, 1992.

3. Feldman, P.L.; Griffith, O.W.; Stuehr, D.J. The surprising life of nitric oxide Chem. Eng. News 71: 26-38, 1993.

4. Kojima, H.; Sakurai, K.; Kikuchi,K.; Kawahara, S.; Kirino, Y.; Nagoshi, H.; Hirata, Y.; Nagano, T. Development of a fluorescent indicator for nitric oxide based on the fluorescein chromophore Chem. Pharm. Bull. (Tokyo) 46: 373-5, 1998.

5. Nagano, T.; Yoshimura, T. Chem. Rev. 102: 1235-70, 2002.

6. Nakatsubo, N.; Kojima, H.; Kikuchi, K.; Nagoshi, H.; Hirata, Y.; Maeda, D.; Imai, Y.; Irimura, T.; Nagano, $\mathrm{T}$. Direct evidence of nitric oxide production from bovine aortic endothelial cells using new fluorescence indicators: diaminofluoresceins. F.E.B.S. Lett. 427; 263-6, 1998.

7. Nagata, N.; Momose, K.; Ishida, Y. J. Inhibitory effects of catecholamines and anti-oxidants on the fluorescence reaction of 4,5-diaminofluorescein, DAF-2, a novel indicator of nitric oxide. Biochem. (Tokyo) 125: 658-61, 1999.

8. Yamamoto, T.; Yuyama, K.; Nakamura, K.; Kato, T., Yamamoto; H. Kinetic characterization of the nitric oxide toxicity for PC12 cells: effect of half-life time of NO release. Eur. J. Pharmacol. 397: 25-33, 2000.

9. Leikert, J.F.; Rathel, T.R.; Muller, C.; Vollmar, A.M.; Dirsch, V.M. Reliable in vitro measurement of nitric oxide released from endothelial cells using low concentrations of the fluorescent probe 4,5diaminofluorescein. F.E.B.S. Lett. 506: 131-4, 2001.

10. Rathel, T.R.; Leikert, J.F.; Vollmar, A.M.; Dirsch, V.M. Application of 4,5-diaminofluorescein to reliably measure nitric oxide released from endothelial cells in vitro. Biol. Proced. Online 5:136-142, 2003.

11. Lebuffe, G.; Schumacker, P.T.; Shao, Z.H.; Anderson, T.; Iwase, H.; Vanden Hoek, T.L. ROS and NO trigger early preconditioning: relationship to mitochondrial KATP channel. Am. J. Physiol. Heart Circ. Physiol. 284: H299-308, 2003.

12. Berkels, R.; Dachs, C.; Roesen, R.; Klaus, W. Simultaneous measurement of intracellular $\mathrm{Ca}(2+)$ and nitric oxide: a new method. Cell Calcium 27: 281-6, 2000.

13. Toomtong, P.; Young, J.D. Nitric oxide production by human peripheral blood mononuclear cells. Ann. Acad. Med. Singapore 30: 270-3, 2001.

14. Rhinehart, K.L.; Pallone, T.L. Nitric oxide generation by isolated descending vasa recta. Am. J. Physiol. Heart Circ. Physiol. 281: H316-24, 2001.

15. Sutherland, H.; Khundkar, R.; Zolle, O.; McArdle, A.; Simpson, A.W.; Jarvis, J.C.; Salmons, S. A fluorescence-based method for measuring nitric oxide in extracts of skeletal muscle. Nitric Oxide 5: 47581, 2001.

16. Dedkova, E.N.; Blatter, L.A. Nitric oxide inhibits capacitative $\mathrm{Ca} 2+$ entry and enhances endoplasmic reticulum Ca2+ uptake in bovine vascular endothelial cells. J. Physiol. 539: 77-91, 2002.

17. Lorenz, P.; Roychowdhury, S.; Engelmann, M.; Wolf, G.; Horn, T.F. Oxyresveratrol and resveratrol are potent antioxidants and free radical scavengers: effect on nitrosative and oxidative stress derived from microglial cells. Nitric Oxide 9: 64-76, 2003.

18. Navarro-Antolin, J.; Lamas, S. Nitrosative stress by cyclosporin A in the endothelium: studies with the NO-sensitive probe diaminofluorescein-2/diacetate using flow cytometry. Nephrol. Dial. Transplant. 16 Suppl. 1: 6-9, 2001.

19. Havenga, M.J., van Dam, B., Groot, B.S., Grimbergen, J.M., Valerio, D., Bout, A., Quax, P.H. Anal. Biochem. (2001) 290, 283-91.

20. Itoh, Y.; Ma, F.H.; Hoshi, H.; Oka, M.; Noda, K.; Ukai, Y.; Kojima, H.; Nagano, T.; Toda, N. Determination and bioimaging method for nitric oxide in biological specimens by diaminofluorescein fluorometry. Anal. Biochem. 287: 203-9, 2000.

21. Kojima, H.; Nakatsubo, N.; Kikuchi, K.; Kawahara, S.; Kirino, Y.; Nagoshi, H.; Hirata, Y.; Nagano, T. Detection and imaging of nitric oxide with novel fluorescent indicators: diaminofluoresceins. Anal. Chem. 70: 2446-53, 1998.

22. Kojima, H.; Nakatsubo, N.; Kikuchi, K.; Urano, Y.; Higuchi, T.; Tanaka, J.; Kudo, Y.; Nagano, T. Direct evidence of NO production in rat hippocampus and cortex using a new fluorescent indicator: DAF-2 DA. Neuroreport 9: 3345-8, 1998. 


\section{Performance of DAF-2 for NO Imaging}

23. Goetz, R.M.; Thatte, H.S.; Prabhakar, P.; Cho, M.R.; Michel, T.; Golan, D.E. Estradiol induces the calcium-dependent translocation of endothelial nitric oxide synthase. Proc. Natl. Acad. Sci. U. S. A. 96: 2788-93, 1999.

24. Igarashi, J.; Thatte, H.S.; Prabhakar, P.; Golan, D.E.; Michel, T. Calcium-independent activation of endothelial nitric oxide synthase by ceramide. Proc. Natl. Acad. Sci. U. S. A. 96: 12583-8, 1999.

25. Brown, L.A.; Key, B.J.; Lovick, T.A. Bio-imaging of nitric oxide-producing neurones in slices of rat brain using 4,5-diaminofluorescein. J. Neurosci. Methods 92: 101-10, 1999.

26. Lopez-Figueroa, M.O.; Caamano, C.; Morano, M.I.; Ronn, L.C.; Akil, H.; Watson, S.J. Direct evidence of nitric oxide presence within mitochondria. Biochem. Biophys. Res. Commun. 272: 129-33, 2000.

27. Brown, L.A.; Key, B.J.; Lovick, T.A. Fluorescent imaging of nitric oxide production in neuronal varicosities associated with intraparenchymal arterioles in rat hippocampal slices. Neurosci. Lett. 294: 9$12,2000$.

28. Foissner, I.; Wendehenne, D.; Langebartels, C.; Durner, J. In vivo imaging of an elicitor-induced nitric oxide burst in tobacco. Plant. J. 23: 817-24, 2000.

29. Yoshioka, T.; Iwamoto, N.; Tsukahara, F.; Irie, K.; Urakawa, I.; Muraki, T. Anti-NO action of carvedilol in cell-free system and in vascular endothelial cells. Br. J. Pharmacol. 129: 1530-5, 2000.

30. Blute, T.A.; Lee, M.R.; Eldred, W.D. Direct imaging of NMDA-stimulated nitric oxide production in the retina. Vis. Neurosci. 17: 557-66, 2000.

31. Li, D.; Shirakami, G.; Zhan, X.; Johns, R.A. Regulation of ciliary beat frequency by the nitric oxide-cyclic guanosine monophosphate signaling pathway in rat airway epithelial cells. Am. J. Respir. Cell. Mol. Biol. 23: $175-81,2000$.

32. Kimura, C.; Koyama, T.; Oike, M.; Ito, Y. Hypotonic stress-induced NO production in endothelium depends on endogenous ATP. Biochem. Biophys. Res. Commun. 274: 736-40, 2000.

33. Willmott, N.J.; Wong, K.; Strong, A.J. A fundamental role for the nitric oxide-G-kinase signaling pathway in mediating intercellular $\mathrm{Ca}(2+)$ waves in glia. J. Neurosci. 20: 1767-79, 2000.

34. Lopez-Figueroa, M.O.; Caamano, C.; Marin, R.; Guerra, B.; Alonso, R.; Morano, M.I.; Akil, H.; Watson, S.J. Characterization of basal nitric oxide production in living cells. Biochim. Biophys. Acta 1540: 253-64, 2001.

35. Sugimoto, K.; Fujii, S.; Takemasa, T.; Yamashita, K. Detection of intracellular nitric oxide using a combination of aldehyde fixatives with 4,5-diaminofluorescein diacetate. Histochem. Cell. Biol. 113: 3417, 2000.

36. Choi, Y.B.; Tenneti, L.; Le, D.A.; Ortiz, J.; Bai, G.; Chen, H.S.; Lipton, S.A. Molecular basis of NMDA receptor-coupled ion channel modulation by S-nitrosylation. Nat. Neurosci. 3: 15-21, 2000.

37. Gorbunov, N.V.; Pogue-Geile, K.L.; Epperly, M.W.; Bigbee, W.L.; Draviam, R.; Day, B.W.; Wald, N.; Watkins, S.C.; Greenberger, J.S. Activation of the nitric oxide synthase 2 pathway in the response of bone marrow stromal cells to high doses of ionizing radiation. Radiat. Res. 154: 73-86, 2000.

38. Kojima, H.; Hirata, M.; Kudo, Y.; Kikuchi, K.; Nagano, T. Visualization of oxygen-concentrationdependent production of nitric oxide in rat hippocampal slices during aglycemia. J. Neurochem. 76: 1404$10,2001$.

39. Pfarr, K.M.; Qazi, S.; Fuhrman, J.A. Nitric oxide synthase in filariae: demonstration of nitric oxide production by embryos in Brugia malayi and Acanthocheilonema viteae. Exp. Parasitol. 97: 205-14, 2001.

40. Kimura, C., Oike, M., Koyama, T., Ito, Y. Am. J. Physiol. Endocrinol. Metab. (2001) 280, E171-8.

41. Takeno, S.; Osada, R.; Furukido, K.; Chen, J.H.; Yajin, K. Increased nitric oxide production in nasal epithelial cells from allergic patients--RT-PCR analysis and direct imaging by a fluorescence indicator: DAF-2 DA. Clin. Exp. Allergy 31: 881-8, 2001.

42. Qiu, W.; Kass, D.A.; Hu, Q.; Ziegelstein, R.C. Determinants of shear stress-stimulated endothelial nitric oxide production assessed in real-time by 4,5-diaminofluorescein fluorescence. Biochem. Biophys. Res. Commun. 286: 328-35, 2001.

43. Montagnani, M.; Chen, H.; Barr, V.A.; Quon, M.J. Insulin-stimulated activation of eNOS is independent of $\mathrm{Ca} 2+$ but requires phosphorylation by Akt at Ser(1179). J. Biol. Chem. 276: 30392-8, 2001.

44. Maffei, A., Poulet, R., Vecchione, C., Colella, S., Fratta, L., Frati, G., Trimarco, V., Trimarco, B., Lembo, G. J. Hypertens. (2002) 20, 1135-42.

45. Schuppe, H.; Cuttle, M.; Chad, J.E.; Newland, P.L. 4,5-diaminofluoroscein imaging of nitric oxide synthesis in crayfish terminal ganglia. J. Neurobiol. 53: 361-9, 2002.

46. Li, N.; Yi, F.X.; Rute, E.; Zhang, D.X.; Slocum, G.R.; Zou, A.P. Effects of homocysteine on intracellular nitric oxide and superoxide levels in the renal arterial endothelium. Am. J. Physiol. Heart. Circ. Physiol. 283: H1237-43, 2002. 


\section{Performance of DAF-2 for NO Imaging}

47. Yamamoto, Y.; Henrich, M.; Snipes, R.L.; Kummer, W. Altered production of nitric oxide and reactive oxygen species in rat nodose ganglion neurons during acute hypoxia. Brain Res. 961: 1-9, 2003.

48. Vecchione, C.; Aretini, A.; Maffei, A.; Marino, G.; Selvetella, G.; Poulet, R.; Trimarco, V.; Frati, G.; Lembo, G. Cooperation between insulin and leptin in the modulation of vascular tone. Hypertension 42: 166-70, 2003.

49. Li, N.; Sul, J.Y.; Haydon, P.G. A calcium-induced calcium influx factor, nitric oxide, modulates the refilling of calcium stores in astrocytes. J. Neurosci. 23: 10302-10, 2003.

50. Lacza, Z.; Snipes, J.A.; Zhang, J.; Horvath, E.M.; Figueroa, J.P.; Szabo, C.; Busija, D.W. Mitochondrial nitric oxide synthase is not eNOS, nNOS or iNOS. Free Radic. Biol. Med. 35: 1217-28, 2003.

51. Takagi, K.; Kawaguchi, Y.; Hara, M.; Sugiura, T.; Harigai, M.; Kamatani, N. Serum nitric oxide (NO) levels in systemic sclerosis patients: correlation between NO levels and clinical features. Clin. Exp. Immunol. 134: 538-44, 2003.

52. Shao, C.; Stewart, V.; Folkard, M.; Michael, B.D.; Prise, K.M. Nitric oxide-mediated signaling in the bystander response of individually targeted glioma cells. Cancer Res. 63: 8437-42, 2003.

53. Kono, T.; Chisato, N.; Ebisawa, Y.; Asama, T.; Sugawara, M.; Ayabe, T.; Kohgo, Y.; Kasai, S.; Yoneda, M.; Takahashi, T. Impaired nitric oxide production of the myenteric plexus in colitis detected by a new bioimaging system. J. Surg. Res. 117: 329-38, 2004.

54. Kimura, C.; Oike, M.; Ohnaka, K.; Nose, Y.; Ito, Y. Constitutive nitric oxide production in bovine aortic and brain microvascular endothelial cells: a comparative study. J. Physiol. 554: 721-30, 2004.

55. Ebisawa, Y.; Kono, T.; Yoneda, M.; Asama, T.; Chisato, N.; Sugawara, M.; Ishikawa, K.; Iwamoto, J.; Ayabe, T.; Kohgo, Y.; Kasai, S. Direct evidence that induced nitric oxide production in hepatocytes prevents liver damage during lipopolysaccharide tolerance in rats. J. Surg. Res. 118: 183-9, 2004.

56. Ortiz, P.A.; Hong, N.J.; Garvin, J.L. Luminal flow induces eNOS activation and translocation in the rat thick ascending limb. II. Role of PI3-kinase and Hsp90. Am. J. Physiol. Renal Physiol. 287: F281-8, 2004.

57. Quintana, E.; Hernandez, C.; Alvarez-Barrientos, A.; Esplugues, J.V.; Barrachina, M.D. Synthesis of nitric oxide in postganglionic myenteric neurons during endotoxemia: implications for gastric motor function in rats. F.A.S.E.B. J. 18, 531-3, 2004.

58. Qi, K.; Qiu, H.; Rutherford, J.; Zhao, Y.; Nance D.M.; Orr, F.W. Direct visualization of nitric oxide release by liver cells after the arrest of metastatic tumor cells in the hepatic microvasculature. J. Surg. Res. 119: 29-35, 2004.

59. Bryan, N.S.; Rassaf, T.; Maloney, R.E.; Rodriguez, C.M.; Saijo, F.; Rodriguez, J.R.; Feelisch, M. Cellular targets and mechanisms of nitros(yl)ation: an insight into their nature and kinetics in vivo. Proc. Natl. Acad. Sci. U. S. A. 101: 4308-13, 2004.

60. Rodriguez, J.; Maloney, R.E.; Rassaf, T.; Bryan, N.S.; Feelisch, M. Chemical nature of nitric oxide storage forms in rat vascular tissue. Proc. Natl. Acad. Sci. U. S. A. 100, 336-41, 2003.

61. Dejam, A.; Kleinbongard, P.; Rassaf, T.; Hamada, S.; Gharini, P.; Rodriguez, J.; Feelisch, M.; Kelm, M. Thiols enhance NO formation from nitrate photolysis. Free Radic. Biol. Med. 35, 1551-9, 2003.

62. Broillet, M.; Randin, O.; Chatton, J. Photoactivation and calcium sensitivity of the fluorescent NO indicator 4,5-diaminofluorescein (DAF-2): implications for cellular NO imaging. F.E.B.S. Lett. 491: 22732, 2001.

63. Suzuki, N.; Kojima, H.; Urano, Y.; Kikuchi, K.; Hirata, Y.; Nagano, T. Orthogonality of calcium concentration and ability of 4,5-diaminofluorescein to detect NO. J. Biol. Chem. 277: 47-9, 2002. Erratum in: J. Biol. Chem. 277: 15220, 2002.

64. Uppu, R. M. and Pryor, W. A. Nitrosation of 1,2-phenylenediamine by peroxynitrite/CO2: evidence for a free radical mechanism. J. Am. Chem. Soc.121, 9738-9739, 1999.

65. Jourd'heuil, D. Increased nitric oxide-dependent nitrosylation of 4,5-diaminofluorescein by oxidants: implications for the measurement of intracellular nitric oxide. Free Radic. Biol. Med. 33: 676-84, 2002.

66. Zhang, X.; Kim, W.S.; Hatcher, N.; Potgieter, K.; Moroz, L.L.; Gillette, R.; Sweedler, J.V. Interfering with nitric oxide measurements. 4,5-diaminofluorescein reacts with dehydroascorbic acid and ascorbic acid. $J$. Biol. Chem. 277: 48472-8, 2002.

67. Espey, M.G.; Miranda, K.M.; Thomas, D.D.; Wink, D.A. Distinction between nitrosating mechanisms within human cells and aqueous solution. J. Biol. Chem. 276: 30085-91, 2001.

68. Dejam A, Hunter CJ, Schechter AN, Gladwin MT. Emerging role of nitrite in human biology. Blood Cells Mol Dis. 32:423-9, 2004.

69. Liu, X.; Miller, M.J.; Joshi, M.S.; Thomas, D.D.; Lancaster, J.R. Jr. Accelerated reaction of nitric oxide with $\mathrm{O} 2$ within the hydrophobic interior of biological membranes. Proc. Natl. Acad. Sci. U. S. A. 95: 21759, 1998. 


\section{Performance of DAF-2 for NO Imaging}

70. Ekani-Nkodo, A; Fygenson, D.K. Size exclusion and diffusion of fluoresceinated probes within collagen fibrils. Phys. Rev. E 67: 021909, 2003.

71. Ghafourifar, P.; Colton, CA Compartmentalized nitrosation and nitration in mitochondria. Antioxid Redox Signal. 5: 349-54, 2003.

72. Bryan, N.S., Rassaf, T., Maloney, RE., Rodriguez, CM., Saijo, F., Rodriguez, JR., Feelisch, M. unpublished data. 
Performance of DAF-2 for NO Imaging

\section{TABLE AND FIGURE LEGENDS}

\section{Table 1}

Protocols followed with the samples designated for fluorometric and HPLC analysis. Samples were subsequently soaked in DMSO and shaken for 1 hour at in a water bath at $37^{\circ} \mathrm{C}$ to extract fluorophores within. The supernatant (DMSO and solutes) was characterized by fluorometry and HPLC techniques.

\section{Figure 1}

Concentration response curves for DAF-2 T formation from DAF-2 loaded media incubated with varying concentrations of the NO donor MAHMA-NOnoate. The vertical axis represents DAF-2 $\mathrm{T}$ fluorescence expressed as a fraction of the fluorescence from unactivated samples (autofluorescence). The solid squares represent values obtained (a) from plate reader experiments with $10 \mu \mathrm{m}$ DAF-2 in buffer solutions, and (b) from fluorescence microscopy experiments performed on aortic tissues incubated with buffer solutions containing $10 \mu \mathrm{m}$ DAF-2 DA. The solid lines correspond to curve fits to an equation of the form $\mathrm{y}=\mathrm{Ax}$ and a statistical weighting $\mathrm{w}_{\mathrm{i}}=1 / \mathrm{y}_{\mathrm{i}}$.

\section{Figure 2}

Fluorescence spectroscopy performed on DMSO extracts from aortic samples, following the protocols outlined in Table 1 and further diluted in PBS (total dilution 1:2500). The spectra from these samples are contrasted with a sample of DAF-2 T (100 nM) in the same buffer solution.

\section{Figure 3}

Quenching of DAF-2 $\mathrm{T}$ formation at varying concentrations of two endogenous antioxidants, ascorbate (Asc) and glutathione (GSH).

\section{Figure 4}

Panel A shows an aortic segment incubated with DAF-2 DA $(10 \mu \mathrm{M})$ for 60 min and the NOdonor MAHMA-NONOate $(200 \mu \mathrm{M})$, and viewed under fluorescence microscopy. For contrast, panel B depicts a similar cross-section of an aortic segment stained with H\&E, and viewed under bright field microscopy. The similarity in staining patterns suggest that DAF-2 is significantly compartmentalized around the elastic laminae. Panel $\mathrm{C}$ represents a typical image obtained from a tissue incubated with DAF-2 DA under basal conditions (no NO-donor). Upon continuous exposure to UV light of $350 \mathrm{~nm}$, the same tissue becomes increasing fluorescent, as shown in the sequence $\mathrm{D}$ and $\mathrm{E}$. The white bars in panels $\mathrm{A}$ and $\mathrm{C}$ represent $20 \mu \mathrm{m}$ for the upper and lower panels, respectively. Panels $\mathrm{C}$ through $\mathrm{E}$ are depicted in a false-color scale, whereby the rainbow progression of colors from violet to red represent increasing levels of intensity.

\section{Figure 5}

Action spectra of NO formation in aortic tissues by UV illumination, assessed by (a) DAF-2 nitrosation, and (b) cGMP formation. Both spectra indicate that the photoactive species responsible absorbs strongly at or below $310 \mathrm{~nm}$. Each of the cGMP points shown represents the outcome of 4-6 experiments that were processed as described in the Methods section. 


\begin{tabular}{|c|c|c|c|c|}
\hline SAMPLE & \multicolumn{4}{|c|}{ ORGAN BATH INCUBATION SEQUENCE } \\
\hline & $90 \mathrm{~min}$ & $10 \mathrm{~min}$ & $60 \mathrm{~min}$ & $15 \mathrm{~min}$ \\
\hline $\mathbf{1}$ & equilibration & - & - & - \\
$\mathbf{2}$ & equilibration & L-NIO & DAF-2 DA $10 \mathrm{uM}$ & - \\
$\mathbf{3}$ & equilibration & - & DAF-2 DA $10 \mathrm{uM}$ & - \\
$\mathbf{4}$ & equilibration & - & DAF-2 DA $10 \mathrm{uM}$ & $350 \mathrm{~nm}$ light \\
$\mathbf{5}$ & equilibration & L-NIO & DAF-2 DA $10 \mathrm{uM}$ & 1 mM MAHMANO \\
\hline
\end{tabular}

Table 1 

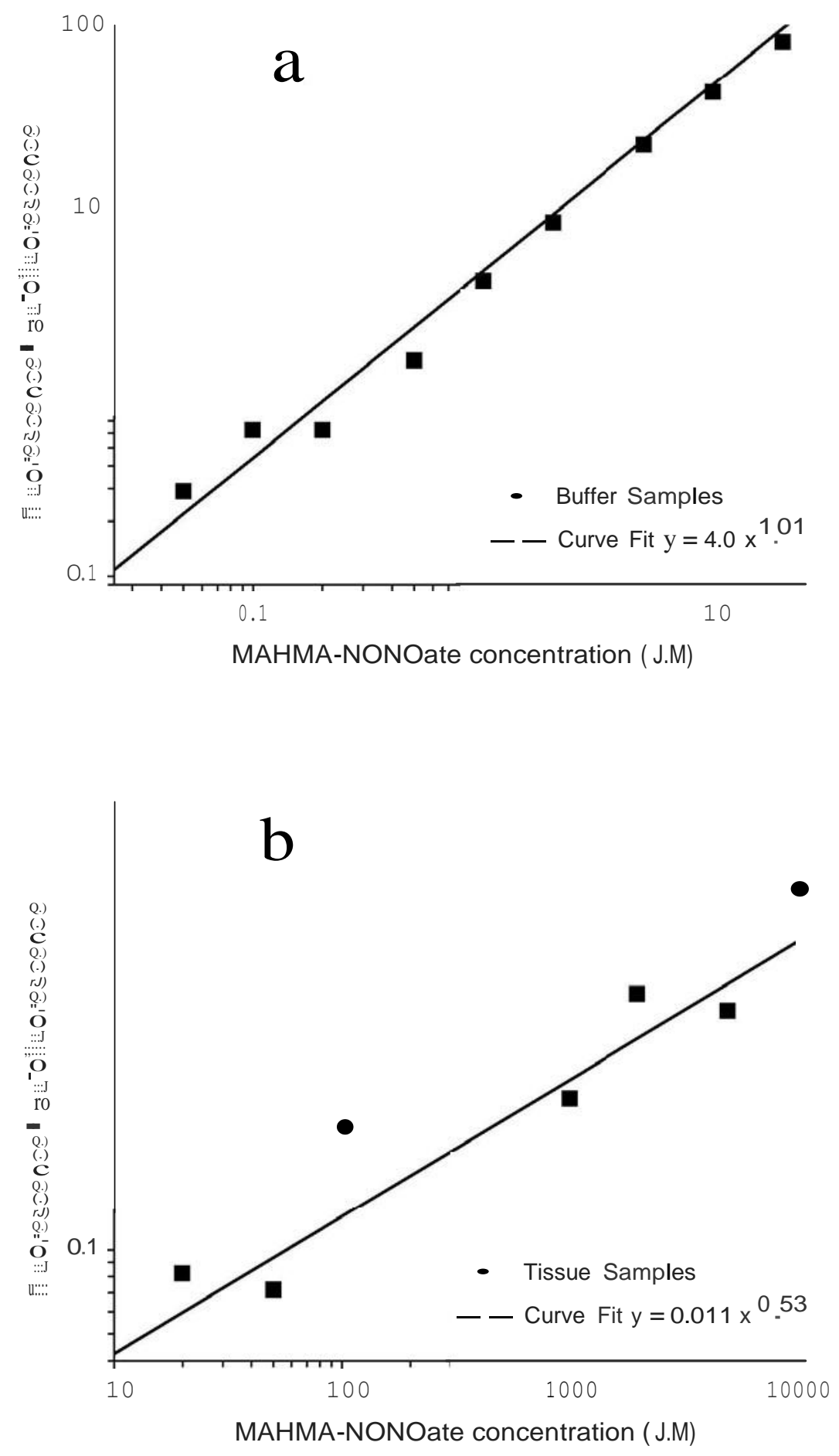

Figure 1. 
Performance of DAF-2 for NO Imaging

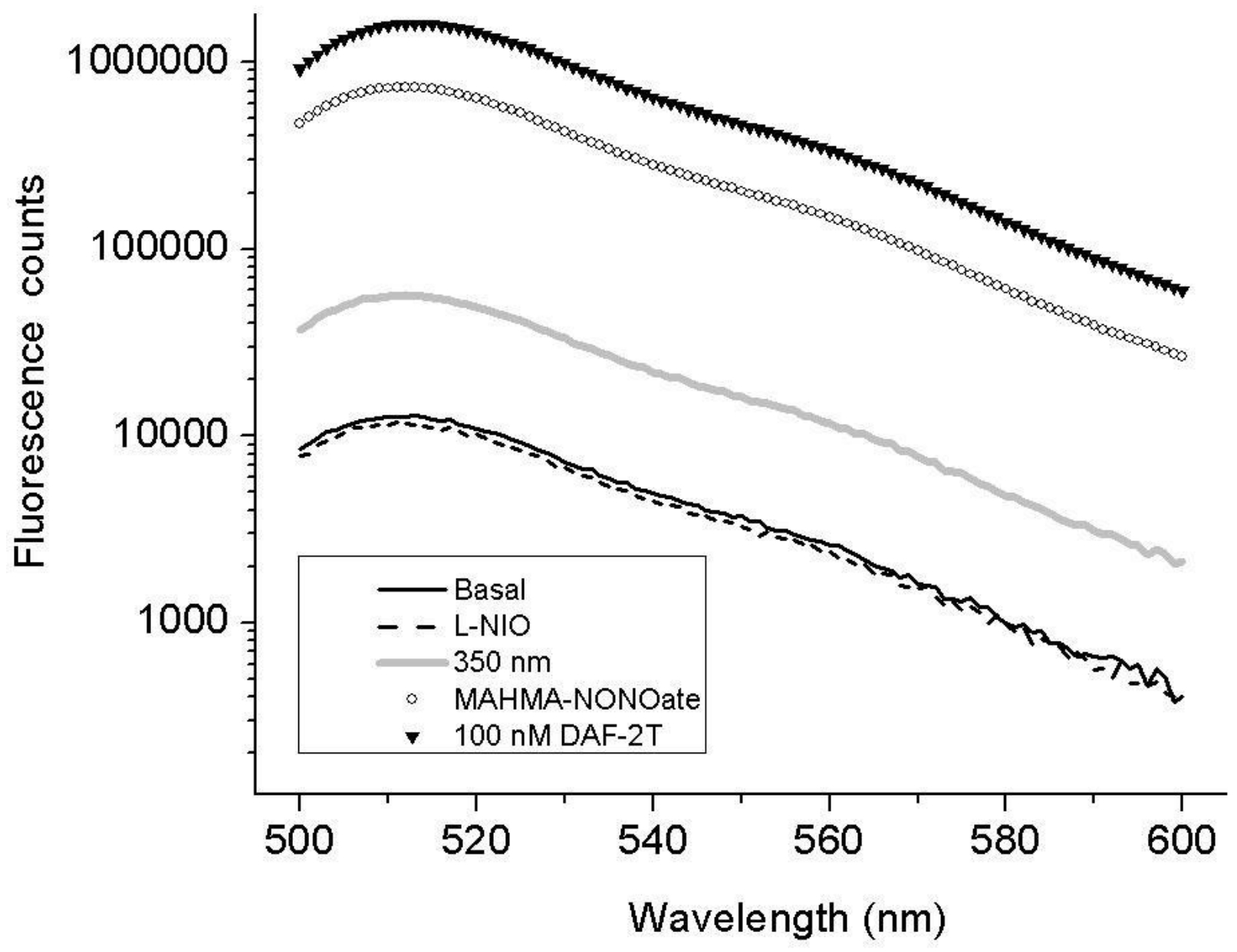

Figure 2 

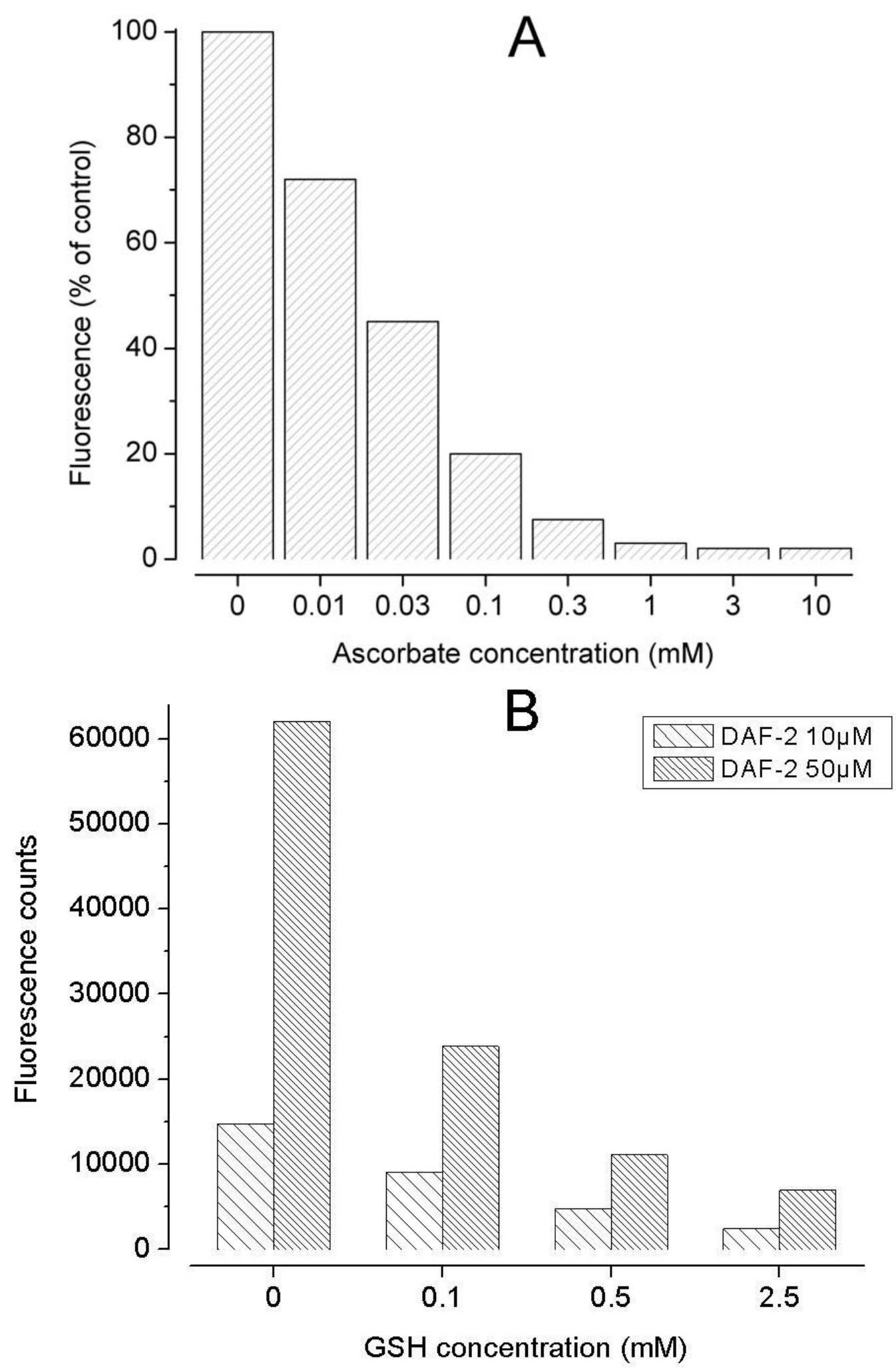

Fig. 3. 
Performance of DAF-2 for NO Imaging
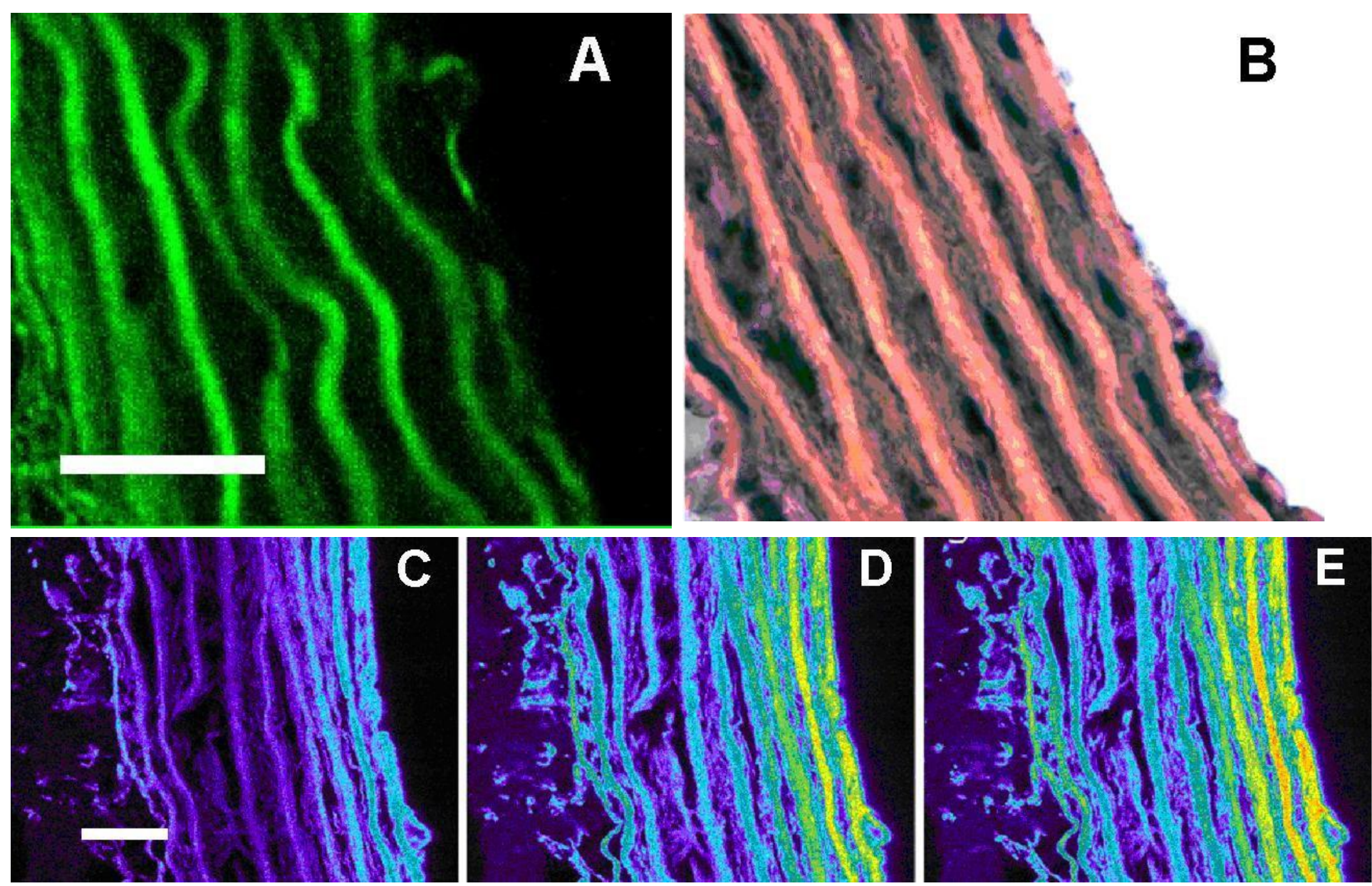

Fig. 4. 
Performance of DAF-2 for NO Imaging

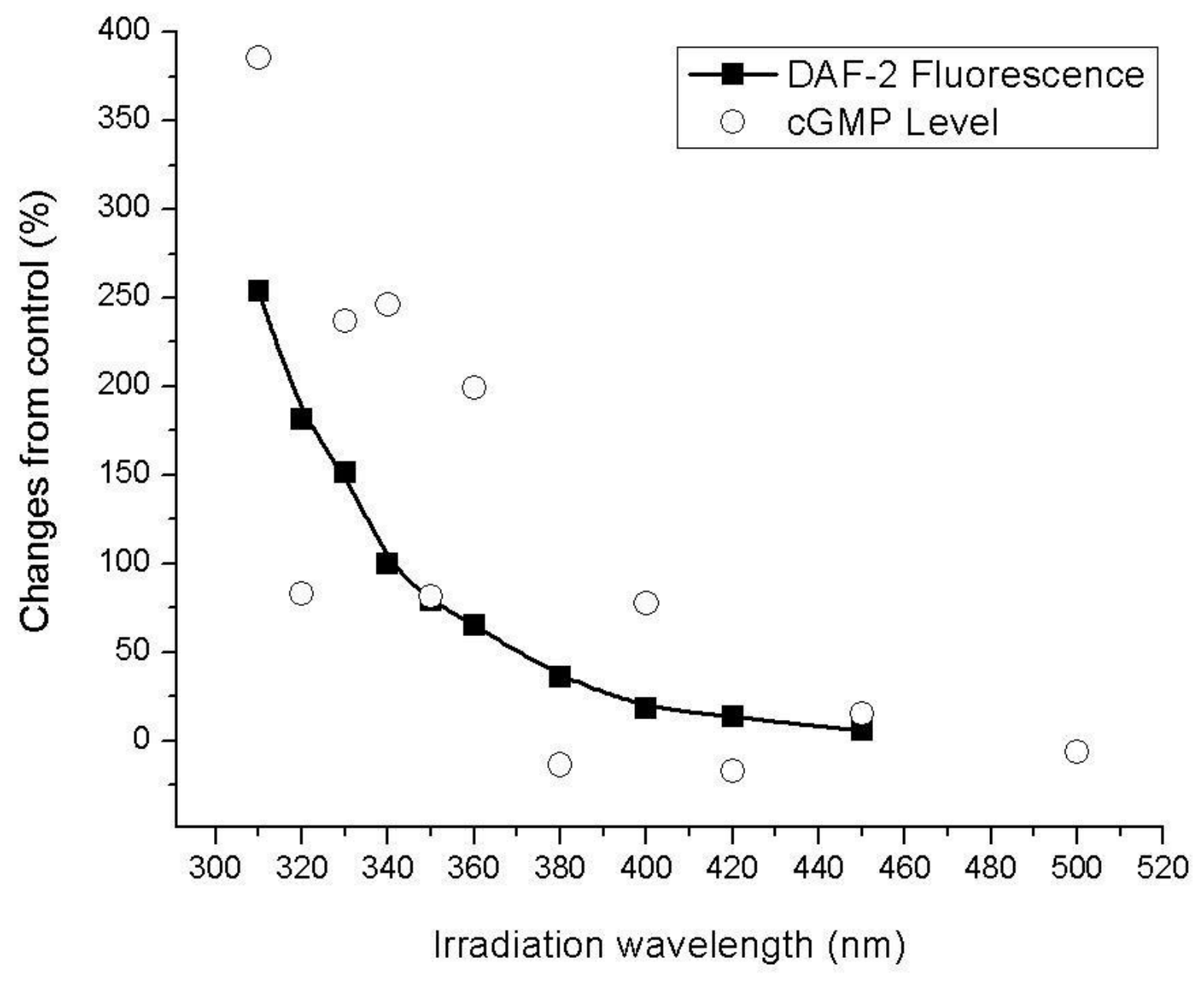

Figure 5 